\title{
Epidemiological Data on LCL and PCL Injuries Over 17 Seasons in Men's Professional Soccer: The UEFA Elite Club Injury Study
}

This article was published in the following Dove Press journal: Open Access Journal of Sports Medicine

\author{
Matilda Lundblad ${ }^{1,2}$ \\ Martin Hägglund (iD) ${ }^{2,3}$ \\ Christoffer Thomeé (DD ${ }^{2}$ \\ Eric Hamrin Senorski (iD ${ }^{4}$ \\ Jan Ekstrand ${ }^{2,5}$ \\ Jón Karlsson ${ }^{1,2}$ \\ Markus Waldén ${ }^{2,5}$ \\ 'Department of Orthopedics, Institute of \\ Clinical Sciences, Sahlgrenska Academy, \\ University of Gothenburg, Gothenburg, \\ Sweden; ${ }^{2}$ Football Research Group, \\ Linköping University, Linköping, Sweden; \\ ${ }^{3}$ Division of Physiotherapy, Department \\ of Medical and Health Sciences, Linköping \\ University, Linköping, Sweden; \\ ${ }^{4}$ Department of Health and \\ Rehabilitation, Institute of Neuroscience \\ and Physiology, Sahlgrenska Academy, \\ University of Gothenburg, Gothenburg, \\ Sweden; ${ }^{5}$ Division of Community \\ Medicine, Department of Medical and \\ Health Sciences, Linköping University, \\ Linköping, Sweden
}

Correspondence: Matilda Lundblad Department of Orthopedics, Institute of Clinical Sciences, Sahlgrenska Academy, University of Gothenburg Göteborgsvägen

3I, Mölndal SE-43I80, Sweden

$\mathrm{Tel}+46-76 \mathrm{I}-050606$

Email matildalundblad@gmail.com
Background: There is limited epidemiological information on injury rates and injury mechanisms for lateral collateral ligament (LCL) and posterior cruciate ligament (PCL) injuries in male professional soccer. In addition, time trends and lay-off times for these injuries have not yet been determined.

Aim: To determine injury rates and circumstances of LCL and PCL injuries over 17 seasons in men's professional soccer.

Methods: A prospective cohort study, in which 68 professional European soccer teams were followed over 17 consecutive seasons (2001/2002 to 2017/2018). The teams' medical staff recorded player exposure and time-loss injuries. Lay-off time was reported as the median and the first and third quartile. Injury rate was defined as the number of injuries per 1000 playerhours.

Results: One hundred and twenty-eight LCL and 28 PCL injuries occurred during $2,554,686 \mathrm{~h}$ of exposure (rate 0.05 and $0.01 / 1000 \mathrm{~h}$, respectively). The median lay-off time for $\mathrm{LCL}$ injuries was $15\left(\mathrm{Q}_{1}=7, \mathrm{Q}_{3}=32\right)$ days, while it was 31 days for PCL injuries $\left(\mathrm{Q}_{1}=15, \mathrm{Q}_{3}=74\right)$. The match injury rate for LCL injuries was 11 times higher than the training injury rate $(0.21 \mathrm{vs}$ $0.02 / 1000 \mathrm{~h}$, rate ratio $[R R] 10.5,95 \%$ CI 7.3 to $15.1 \mathrm{p}<0.001)$ and the match injury rate for PCL injuries was 20 times higher than the training injury rate $(0.056$ vs $0.003 / 1000 \mathrm{~h}$, RR $20.1,95 \%$ CI 8.2 to $49.6, \mathrm{p}<0.001)$. LCL injuries saw a significant annual decrease of approximately $3.5 \%$ $(\mathrm{p}=0.006)$. In total, $58 \%(63 / 108)$ of all LCL injuries and $54 \%(14 / 26)$ of all PCL injuries were related to contact mechanism.

Conclusion: This study with prospectively registered data on LCL and PCL injuries in men's professional soccer shows that the median lay-off from soccer for LCL and PCL injuries is approximately 2 and 4 weeks respectively. These rare knee ligament injuries typically occur during matches and are associated with a contact injury mechanism.

Keywords: football, epidemiology, knee, ligament

\section{Introduction}

Knee injuries are common in male professional soccer players, ${ }^{1}$ where the anterior cruciate ligament (ACL) injury has interested many researchers. ${ }^{2-7}$ There is, however, a paucity of studies which focus primarily on injuries to the other major knee ligaments. Previous studies from the Union of European Football Associations (UEFA) Elite Club Injury Study have reported on ACL injuries ${ }^{8-12}$ and on medial collateral ligament (MCL) injuries. ${ }^{13,14}$ It has been reported that an MCL injury is around four times more common than an ACL injury in these studies and that MCL injuries involve a considerably higher percentage of contact-related injury 
mechanisms. So far, there are no similar reports of injuries to the lateral collateral ligament (LCL) and posterior cruciate ligament (PCL). It is noteworthy that soccer has been reported to be one of the most common sports causing PCL injuries, ${ }^{15}$ but, in spite of this, PCL injuries have never been specifically investigated in a large injury cohort in professional soccer. One plausible explanation for the discrepancy is that PCL injuries constitute a small proportion of injuries sustained in soccer, as a recent study of cruciate ligament injuries in German professional soccer reported that PCL injuries constituted only $2.0 \%$ of all injuries. ${ }^{16}$

A PCL injury is often referred to as "a dashboard injury", describing the mechanism of PCL injury in motor vehicle accidents, when a posterior force is directed at the tibia with the knee in flexion, due to the sudden impact of the dashboard in a collision, suggesting that a contact mechanism in professional soccer is a frequent cause of PCL injury. In an athletic situation, it has been reported that the most frequent injury mechanism is knee hyperflexion. ${ }^{17,18}$ Moreover, the contact or non-contact situation in which a player runs the greatest risk of sustaining a PCL injury has not been determined. The majority of grade III PCL injuries are associated with multiligament knee injuries and the severity of PCL injuries usually corresponds well with the presence of some other ligamentous injury, ${ }^{19}$ suggesting that lower grades of PCL injuries may have a shorter lay-off.

In contrast to the commonly seen isolated MCL injuries, ${ }^{13,14}$ an injury to the lateral side of the knee usually involves not only the LCL but also damage to multiple structures. ${ }^{20}$ Isolated injuries to the LCL usually involve a lower magnitude of trauma, resulting in a less severe injury to the ligament, while more severe LCL injuries usually require a higher magnitude of force. Isolated high-grade injuries to the LCL are therefore fairly rare. $^{20}$ It is nevertheless important to evaluate the injury mechanisms and epidemiology of LCL injuries in professional soccer and to determine what the prognosis is when these injuries are sustained in terms of lay-off time.

The aim of this study was to investigate the rates and circumstances of LCL and PCL injuries over 17 consecutive seasons in the UEFA Elite Club Injury Study in soccer.

\section{Materials and Methods}

This is a prospective cohort study carried out in collaboration with UEFA, the so-called UEFA Elite Club Injury Study, investigating men's professional soccer in Europe since $2001 .^{21}$ For the purpose of this study, 68 teams with
4389 individual players from the highest national leagues in 19 European countries were followed from 2001 to 2018. All contracted players listed in the first team squads each season were invited to participate in the study. Players who left the team during the season were only included while playing for the team.

\section{Study Design and Definitions}

The full methodology and the development of the study design have previously been reported in detail. ${ }^{22}$ The overall study design followed the consensus on definitions and data collection procedures in studies of soccer injuries. ${ }^{23}$ An overview of the general definitions used in the present study is given in Table 1.

\section{Data Collection}

Baseline data in terms of anthropometrics and dominant leg (preferred kicking leg) were collected at player inclusion every season. Individual player exposure during training and matches was registered in minutes by the teams' medical staff on a standard exposure form sent to the study group every month. Additionally, the teams' medical staff recorded injuries on a standard injury form that was sent to the study group each month. The injury form provided information about the diagnosis, nature and circumstances of injury occurrence. The circumstances include if the injury occurred during match or training, if the injury was sustained in a contact or non-contact situation, and match minute of occurrence, etc. All injuries resulting in a player being unable to participate fully in training or match play (ie, time-loss injuries) were recorded. The player was regarded as injured until the medical team in the club allowed full participation in training and availability for match play. All injuries were followed until the final day of rehabilitation. The study has expanded over the study period and the number of details collected on the standard injury form has increased. Consequently, data on contact/non-contact injury were recorded from the 2004/2005 season, match minute of injury from the 2005/2006 season and specific injury mechanisms from a 20 tick-box list from the 2008/2009 season.

\section{Ethical Approval}

The study design was approved by the UEFA Medical Committee and the UEFA Football Development Division. All players provided written informed consent prior to participation. 
Table I Operational Definitions Used in the Study

\begin{tabular}{|c|c|}
\hline Training session & Team training that involved physical activity under the supervision of the coaching staff \\
\hline Match & Competitive or friendly match against another team \\
\hline Injury & $\begin{array}{l}\text { Injury resulting from playing soccer and leading to a player being unable to participate fully in future training or match play } \\
\text { (ie time-loss injury) }\end{array}$ \\
\hline Rehabilitation & A player was injured until team medical staff allowed full participation in training and availability for match selection \\
\hline Re-injury & $\begin{array}{l}\text { Injury of the same type and at the same site as an index injury occurring no more than two months after a player's return to } \\
\text { full participation from the index injury }\end{array}$ \\
\hline LCL injury & A traumatic distraction injury to the $L C L$ leading to a player being unable to participate fully in training or match play \\
\hline PCL injury & A traumatic distraction injury to the $\mathrm{PCL}$ leading to a player being unable to participate fully in training or match play \\
\hline Slight/minimal injury & Injury causing $0-3$ days' absence from training and match play \\
\hline Mild injury & Injury causing 4-7 days' absence from training and match play \\
\hline Moderate injury & Injury causing 8-28 days' absence from training and match play \\
\hline Severe injury & Injury causing more than 28 days' absence from training and match play \\
\hline Traumatic injury & Injury with sudden onset and known cause \\
\hline Non-contact injury & Injury occurring without any contact with another player or object \\
\hline Contact injury & Injury occurring with contact with another player or object \\
\hline Injury rate & Number of injuries per 1000 player hours $[(\Sigma$ injuries $/ \Sigma$ exposure hours $) \times 1000]$ \\
\hline Injury burden & Number of lay-off days per 1000 player hours $[(\Sigma$ lay-off days $/ \Sigma$ exposure hours $) \times 1000]$ \\
\hline
\end{tabular}

Abbreviations: $\mathrm{LCL}$, lateral collateral ligament; $\mathrm{PCL}$, posterior cruciate ligament.

\section{Statistical Analysis}

All analyses were performed using SAS software version 9.4 (SAS Institute Inc, Cary, NC, USA). Lay-off time is presented as the mean $\pm \mathrm{SD}$, median and range or quartiles $(\mathrm{Q} 1=25$ th percentile and $\mathrm{Q} 3=75$ th percentile). Due to skewed distribution in lay-off time, group differences were analyzed using the Mann-Whitney $U$-test. Chi-square test was used for comparisons between non-ordered categorical variables. Fisher's exact test was used for comparisons between dichotomous variables. Injury rate was reported as the number of injuries per 1000 player-hours. The rate ratio (RR) with $95 \%$ confidence interval (CI) was calculated for comparisons of injury rate between groups. Seasonal trend, expressed as the average annual percentage of change, was analyzed using linear regression with injury rates as the dependent variable. No seasonal trend was analyzed for PCL injuries because of the small number of injuries recorded, with several seasons without any PCL injuries at all. For each seasonal injury, rate and $95 \%$ exact Poisson confidence limits were computed. A 2-year moving average and a log-transformed moving average approach, calculated by summarizing two consecutive seasons, were used to smooth out the large seasonal variation. A binomial test was used to analyze the probability of being injured during the last $15 \mathrm{~min}$ of the first or second half. All tests were two-sided and the significance level was set at $\mathrm{p}<0.05$.

\section{Results}

In all, 2,554,687 $\mathrm{h}$ of exposure $(2,160,908 \mathrm{~h}$ of training and $393,778 \mathrm{~h}$ of match play) were registered. A total of 17,322 injuries were documented, of which $128(0.7 \%)$ were LCL injuries and $28(0.2 \%)$ were PCL injuries. The match injury rate for LCL injuries was almost 11 times higher than the training injury rate $(0.21$ vs $0.02 / 1000 \mathrm{~h}$, RR $10.5,95 \%$ CI 7.3 to $15.1, p<0.001)$. The match injury rate for PCL injuries was 20 times higher than the training injury rate ( 0.056 vs $0.003 / 1000 \mathrm{~h}, \mathrm{RR} 20.1,95 \% \mathrm{CI} 8.2$ to 49.6, $\mathrm{p}<0.001)$ (Table 2).

\section{LCL and PCL Injury Rates per Season}

The LCL injury rate varied between 0.018 and $0.144 / 1000$ $\mathrm{h}$ over the 17 seasons. The overall incidence of LCL injuries was $0.05 / 1000 \mathrm{~h}$, meaning that a team can expect to have 0.28 (95\% CI $0.24-0.33$ ) LCL injuries a season, ie, one LCL injury 
Table 2 Epidemiological Data and Injury Characteristics for LCL and PCL Injuries

\begin{tabular}{|c|c|c|}
\hline & $\begin{array}{l}\text { LCL Injury } \\
(n=\mid 28)\end{array}$ & $\begin{array}{l}\text { PCL Injury } \\
(n=28)\end{array}$ \\
\hline $\begin{array}{l}\text { Injury Severity (Lay-Off Days) } \\
\text { Slight/minimal ( } 0-3 \text { days) } \\
\text { Mild ( } 4-7 \text { days) } \\
\text { Moderate ( } 8-28 \text { days) } \\
\text { Severe (>28 days) }\end{array}$ & $\begin{array}{l}8(6 \%) \\
28(22 \%) \\
57(45 \%) \\
35(27 \%)\end{array}$ & $\begin{array}{l}2(7 \%) \\
0(0 \%) \\
10(36 \%) \\
16(57 \%)\end{array}$ \\
\hline $\begin{array}{l}\text { Overall Lay-Off Days } \\
\text { Mean (SD) } \\
\text { Median (range) }\end{array}$ & $\begin{array}{l}25.4(27.6) \\
15(1 ;|4|)\end{array}$ & $\begin{array}{l}55.9(59.7) \\
30.5(2 ; 196)\end{array}$ \\
\hline $\begin{array}{l}\text { Playing Position } \\
\text { Goalkeeper } \\
\text { Defender } \\
\text { Midfielder } \\
\text { Forward }\end{array}$ & $\begin{array}{l}2(2 \%) \\
47(37 \%) \\
62(48 \%) \\
17(13 \%)\end{array}$ & $\begin{array}{l}2(7 \%) \\
8(29 \%) \\
7(25 \%) \\
11(39 \%)\end{array}$ \\
\hline $\begin{array}{l}\text { Injury Mechanism } \\
\text { Non-contact } \\
\text { Contact player } \\
\text { Contact object }\end{array}$ & $\begin{array}{l}45(42 \%) \\
59(55 \%) \\
4(4 \%)\end{array}$ & $\begin{array}{l}12(46 \%) \\
14(54 \%) \\
0(0 \%)\end{array}$ \\
\hline $\begin{array}{l}\text { Dominant Leg Injured } \\
\text { Yes }\end{array}$ & 76 (59\%) & $13(46 \%)$ \\
\hline $\begin{array}{l}\text { Total injury rate } \\
\text { Training rate } \\
\text { Match rate }\end{array}$ & $\begin{array}{l}0.05 / 1000 \mathrm{~h} \\
0.02 / 1000 \mathrm{~h} \\
0.21 / 1000 \mathrm{~h}\end{array}$ & $\begin{array}{l}0.01 / 1000 h \\
0.003 / 1000 h \\
0.056 / 1000 h\end{array}$ \\
\hline Injury burden ${ }^{c}$ & $1.26 / 1000 \mathrm{~h}$ & $0.61 / 1000 \mathrm{~h}$ \\
\hline
\end{tabular}

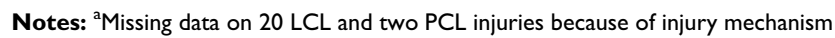
data were collected from 2004/2005. 'Injury rate expressed as the number of injuries/1000 player-hours. 'Injury burden expressed as the number of lay-off days/ 1000 player-hours (injury rate $\times$ mean lay-off).

Abbreviations: LCL, lateral collateral ligament; PCL, posterior collateral ligament; $\mathrm{SD}$, standard deviation.

every third season. The crude LCL injury by season rate and the 2-year moving average injury rate are illustrated in Figure 1. The crude injury rate had a non-significant average annual significant decrease of $4.0 \%(\mathrm{p}=0.08)$, while the $\log$ transformed moving average regression model indicated a significant annual average decrease of approximately $3.5 \%$ ( $\mathrm{R} 2=0.43, \beta=-0.035,95 \% \mathrm{CI}-0.059$ to $-0.012, \mathrm{p}=0.006$ ).

The PCL injury rate varied between 0.0 and 0.040 / $1000 \mathrm{~h}$ over the 17 seasons. The overall incidence for PCL injuries was $0.01 / 1000 \mathrm{~h}$, meaning that a team can expect to have 0.06 (95\% CI 0.04-0.09) PCL injuries a season, ie, one PCL injury every 17 th season.

\section{Lay-Off Time}

The median lay-off time in $L C L$ injuries was $15\left(Q_{1}=7, Q_{3}=32\right)$ days. In total, $59.4 \%(n=76)$ of the LCL injuries affected the dominant leg and $40.6 \%(\mathrm{n}=52)$ affected the non-dominant leg (Table 2). There was no difference in lay-off time between LCL injuries to the dominant leg compared with the nondominant leg (median $=14, Q_{1}=8, Q_{3}=42$ vs median $=15, Q_{1}=8$, $\mathrm{Q}_{3}=32, \mathrm{p}=0.79$ ).

The median lay-off time for PCL injuries was $31\left(\mathrm{Q}_{1}=15\right.$, $\left.\mathrm{Q}_{3}=74\right)$ days. In total, $46.4 \%(\mathrm{n}=13)$ of the PCL injuries affected the dominant leg and $53.6 \%(\mathrm{n}=15)$ affected the nondominant leg (Table 2). There was no difference in lay-off time between PCL injuries to the dominant leg compared with the non-dominant leg (median $=30, Q_{1}=8, Q_{3}=32$ vs median $=31, \mathrm{Q}_{1}=8, \mathrm{Q}_{3}=42, \mathrm{p}=0.82$ ).

\section{Injury Mechanism}

Over 58\% (63/108) of all LCL injuries were due to contact with another player or an object. The most common mechanisms of contact injuries were being tackled (24.4\%) and collision (11.6\%), while twisting/turning was the most common non-contact injury mechanism (23.3\%). There was no difference in lay-off time between contact (median=19, $\mathrm{Q}_{1}=8, \mathrm{Q}_{3}=35$ ) and non-contact (median=11, $\left.\mathrm{Q}_{1}=6, \mathrm{Q}_{3}=32\right)$ injuries $(\mathrm{p}=0.36$ ).

Nearly 54\% (14/26) of all PCL injuries were due to contact with another player or an object. The most common mechanisms of contact injuries were being kicked $(13.6 \%)$, followed by being tackled $(9.1 \%)$ and collision $(9.1 \%)$, while twisting/turning was the most common noncontact injury mechanism (18.2\%). No difference in layoff time between contact (median=26, $\mathrm{Q}_{1}=15, \mathrm{Q}_{3}=85$ ) and non-contact (median=33, $\mathrm{Q}_{1}=12, \mathrm{Q}_{3}=63$ ) injuries was detected $(\mathrm{p}=0.90)$.

\section{Variation of Injury Risk During Matches}

Of the match-related LCL injuries, $48.4 \%$ (30/62) occurred during the last $15 \mathrm{~min}$ of the first or second halves (Figure 2). This number is significantly higher than would be expected, which would be $1 / 3$ of the injuries in each 15 -min period in each half of the game $(\mathrm{p}=0.021)$. There were no differences in the quarterly distribution between the first and second halves ( $\mathrm{p}=0.95$ ).

Of the match-related PCL injuries, 36.8\% (7/19) occurred during the last $15 \mathrm{~min}$ of the first or second halves $(\mathrm{p}=0.73)$ (Figure 3$)$. There were no differences in the quarterly distribution between the first and second halves $(\mathrm{p}=0.73)$.

\section{Re-Injuries}

In total, $8.3 \%$ of all LCL injuries were classified as reinjuries. There was no difference in lay-off time between 


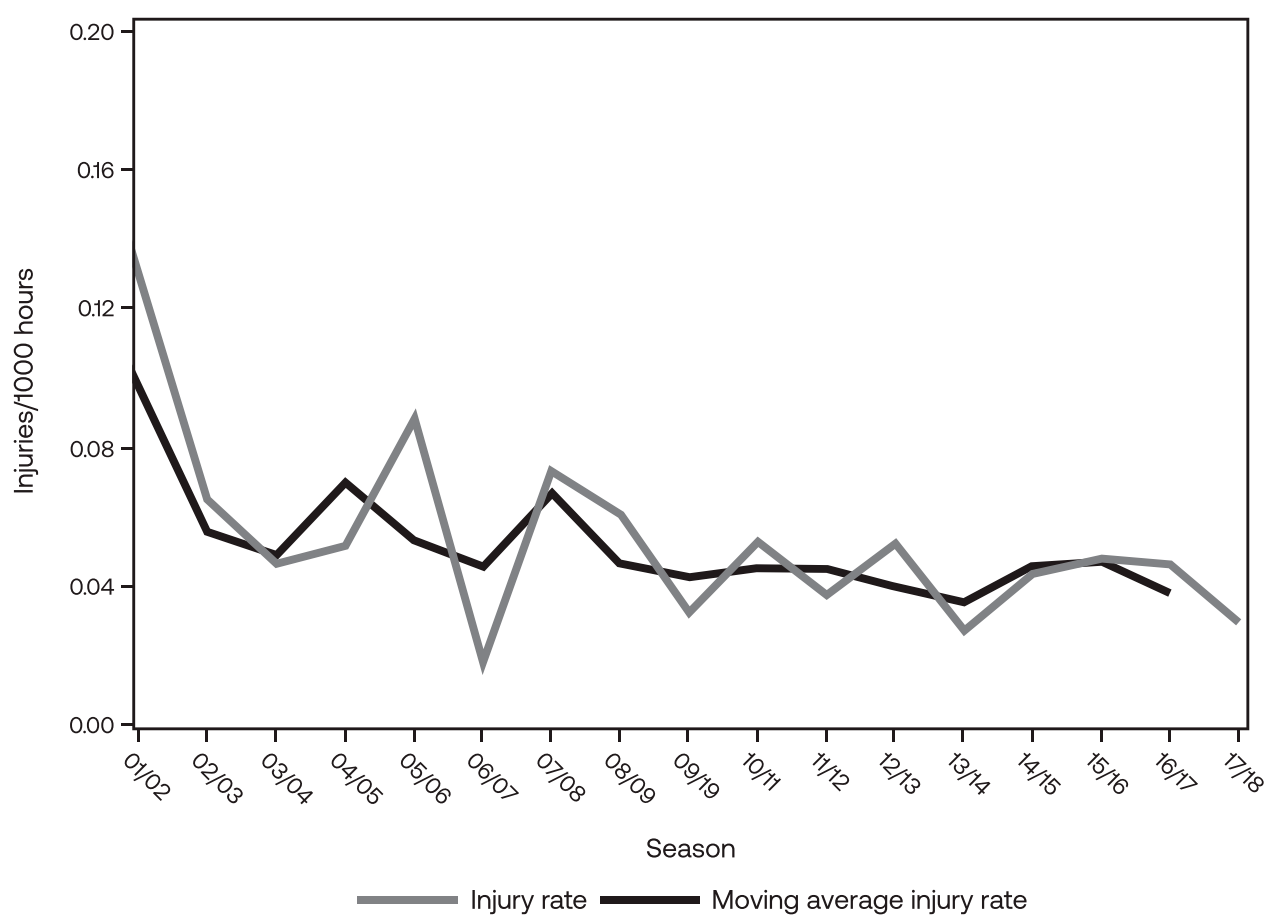

Figure I Seasonal LCL injury rates decrease over 17 professional soccer seasons.

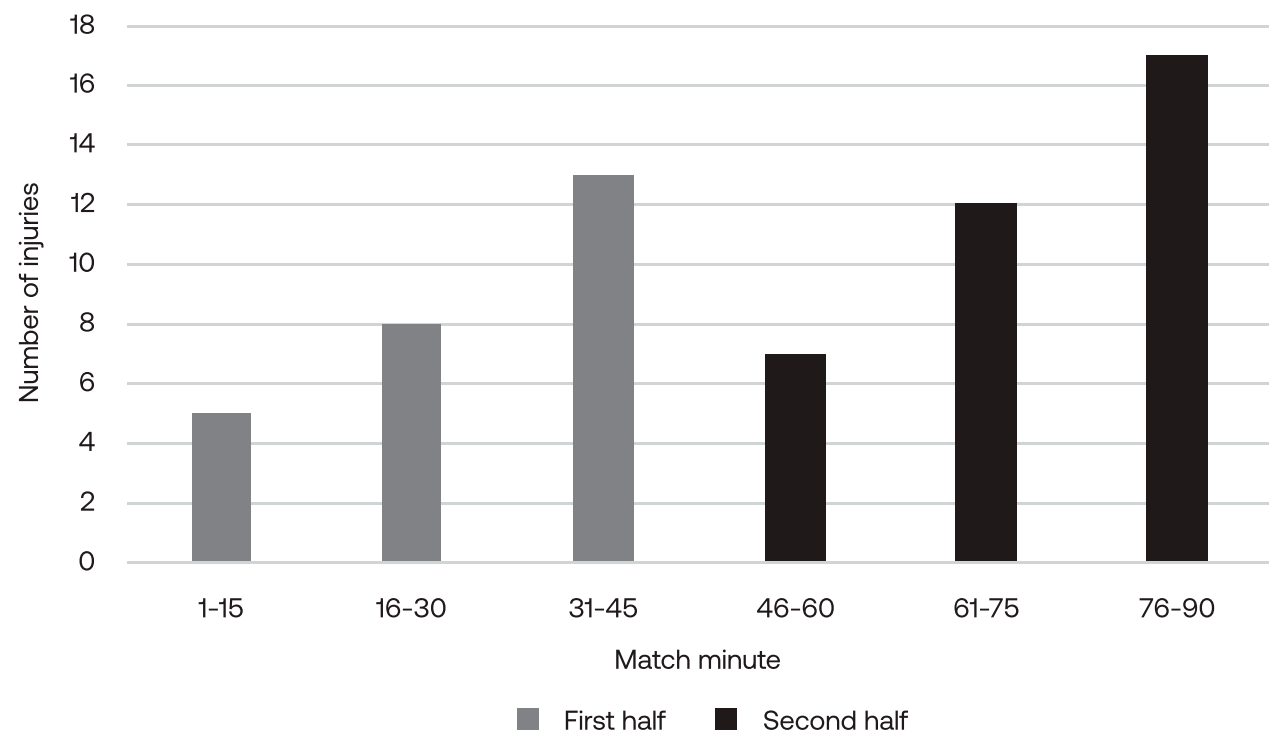

Figure 2 The number of LCL injuries in 15 -min periods for the first $(n=26)$ and second $(n=36)$ match halves.

index injuries (median $=17, \mathrm{Q}_{1}=8, \mathrm{Q}_{3}=37$ ) and re-injuries (median $=14, \mathrm{Q}_{1}=11, \mathrm{Q}_{3}=26 ; \mathrm{p}=0.73$ ). One $\mathrm{PCL}$ injury was classified as a re-injury.

\section{Discussion}

The most important finding from 17 consecutive seasons in men's professional soccer in this study was that LCL and PCL injuries were uncommon, and a team can expect one
LCL injury and one PCL injury every third and 17th season, respectively. Both injuries typically occurred during matches and as contact injuries.

\section{Between-Season and Within-Season Variations}

Both LCL and PCL injuries are rare in men's professional soccer, with incidences of 0.05 and 0.01 , respectively, per 


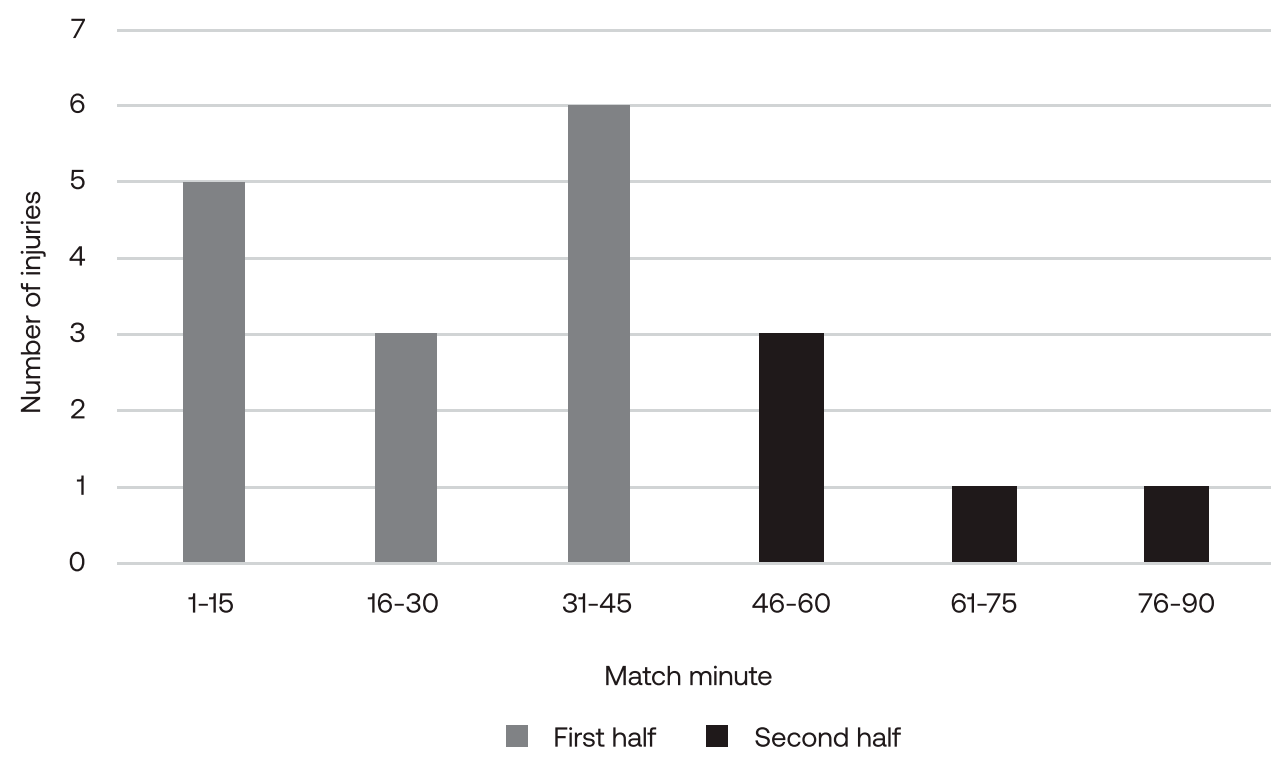

Figure 3 The number of PCL injuries in 15 -min periods for the first $(n=12)$ and second $(n=7)$ match halves.

$1000 \mathrm{~h}$ of exposure. The low incidence of PCL injuries found in this study differs from what was found in the newly implemented professional German football league, where the PCL injuries constituted $2.0 \%$ of injuries overall. The reason for this may be the increase in intensity of the training and match play where $90 \%$ of the injuries occurred during preseason and in players that played in a lower level the previous season. ${ }^{16}$ Also, this was a one season cohort with a considerably smaller study sample. There was an overall decrease in LCL injuries of 3.5\% a year over the 17 -seasonlong study period; this was not possible to compute for PCL injuries, due to the small number of cases. This decrease is promising and in line with the results found for MCL injuries from the same cohort. The reason for this decrease is unknown, but might be related to an increased understanding on how to prevent knee ligaments injuries in general.

\section{Lay-Off Time}

A player who has sustained an LCL or PCL injury can expect a median lay-off time of just over 2 and 4 weeks respectively. In this study, we chose to include all LCL and PCL injuries with a very short lay-off time. Including these injuries gives the study a true reflection on the incidence of LCL and PCL injuries which, according to the medical teams, occur in elite-level soccer. In cases of total PCL injuries, elite-level soccer players sometimes choose to undergo surgical reconstruction of the ligament, although non-surgical treatment including bracing and rehabilitation is a viable option. Future studies may include data on treatment in the analysis of lay-off times for both LCL and PCL injuries in soccer to help clinicians understand the effect of different treatment options.

\section{Injury Mechanism}

In most cases, the LCL and PCL injuries occurred predominantly during contact with another player or object, as has been described previously for MCL injuries. ${ }^{13,14}$ Being tackled was the cause of approximately a quarter of the LCL injuries, while the most common contact mechanism for PCL was being kicked by another player. A contact mechanism as the most common cause of injury is different from ACL, where a non-contact mechanism is the most common. ${ }^{8,24,25}$ There were, however, a number of injuries with non-contact mechanisms for both LCL and PCL injuries. The most common non-contact situation was twisting/ turning and it represented around a fifth of the LCL and PCL injuries. Prevention programs have been reported to reduce injury rates in soccer, ${ }^{26}$ but it is not known whether the use of preventive programs contributed to the small number of LCL and PCL injuries recorded in men's professional soccer.

The LCL is a primary lateral stabilizer of the knee joint. An injury to the LCL is typically caused by excessive varus stress or lateral rotation of the knee when weight-bearing and with the knee in extension. ${ }^{27}$ The findings in this study support this hypothesis, since the most common injury mechanism was contact injury, where it is reasonable to believe that a physical impact on the medial aspect of the leg caused an excessive varus force. 
The most frequent mechanism of PCL injury is a direct blow to the anterior aspect of the knee, resulting in the posterior translation of the tibia. The injury can also occur as a result of hyperextension and rotational or varus/valgus stress, hyper flexion or pivoting, with or without contact. In athletes, the most frequent injury mechanism is knee hyperflexion. ${ }^{17,18}$ The distribution of contact and non-contact PCL injuries was similar. This indicates that there is some variability in the injury mechanism of PCL and it should be noted that rotational trauma might be a common cause.

\section{Variation in Injury Risk During Matches}

Almost half the LCL injuries occurred during the last $15 \mathrm{~min}$ of either the first or second halves, with no difference in the proportion of injuries in either half. The time of LCL injury in soccer is similar to that of MCL injuries, ${ }^{14}$ suggesting that there is an increased risk of sustaining a collateral ligament injury during the last $15 \mathrm{~min}$ of either half during matches. The rationale for why collateral ligament injuries occur during this time period is unknown, but it may be related to increased risk behaviour among players or fatigue, together with contact with other players. To reduce the number of LCL injuries, it may potentially be beneficial for patients to adhere to prevention training, including components of endurance and muscle strength. There was no specific pattern for when PCL injuries occurred during matches and this is likely related to the typical contact mechanism of injury and the low incidence of PCL injuries.

\section{Re-Injuries}

Re-injuries to the LCL occurred in fewer than one in 10 players and did not entail a difference in lay-off time. This indicates that, independent of injury mechanism, LCL injuries are sustained with moderate severity on average in men's professional soccer. The recurrence rate is, however, somewhat lower than the reported recurrence rate for other injuries in the study cohort (12\%). Only one PCL reinjury was recorded during the study period.

\section{Limitations}

There were eight LCL injuries with a lay-off of 0-3 days only and two injuries with a lay-off of 0-7 days for PCL, which are very short lay-off times for knee ligament injuries. Some misdiagnosis within these less severe groups that might explain the recorded injuries can be expected. For instance, it is difficult for clinicians to differentiate between a contusion and a grade I LCL injury with tenderness.
One important factor in epidemiological research projects is the validity of data. The large-scale involvement of different clinicians, from the medical teams at the clubs, in the data collection could be a source of bias. The injury form has also undergone some slight modification during the study period. This explains the missing data on injury mechanism, which was only recorded from 2004, and match minute, which was collected from 2005. Injuries were reported on the basis of clinical examinations, meaning that there was no requirement to confirm the knee ligament injuries with MRI. Therefore, one important aspect to consider in terms of potential limitations is that different examinators were involved in the diagnosis of the injury, ie, the medical teams in each club. There were no specific criteria or recommendations from the study group on how to examine and diagnose injuries including knee ligament injuries. Future studies are warranted to also examine the accuracy of the diagnosis of LCL and PCL injuries among medical teams in men's professional football, as previously has been done for MCL injuries. ${ }^{13}$ The injuries reported in this study were cases in which LCL or PCL injury was reported as the main diagnosis, ie, more LCL and PCL injuries may have occurred during the 17 seasons, with these injuries reported as concomitant injuries. Moreover, it is unknown how potentially concomitant injuries to the LCL or PCL injuries might have affected the outcome, since it is possible that players who sustained an LCL or PCL injury may have associated injuries in terms of meniscal or cartilage injuries. Lay-off times might be influenced by the presence of concomitant injuries to the menisci or articular cartilage.

\section{Conclusion}

This cohort study with prospectively registered data on LCL and PCL injuries in men's professional soccer shows that LCL and PCL injuries are uncommon and the median lay-off from soccer for these injuries is 15 and 31 days, respectively. These knee ligament injuries typically occur during matches and are associated with a contact injury mechanism.

\section{Disclosure}

The authors report no conflicts of interest in this work.

\section{References}

1. Ekstrand J, Krutsch W, Spreco A, et al. Time before return to play for the most common injuries in professional football: a 16-year follow-up of the UEFA elite club injury study. Br J Sports Med. 2020;54(7):421426. doi:10.1136/bjsports-2019-100666 
2. Arundale AJH, Silvers-Granelli HJ, Snyder-Mackler L. Career length and injury incidence after anterior cruciate ligament reconstruction in major league soccer players. Orthop J Sports Med. 2018;6(1):2325967117 750825. doi: $10.1177 / 2325967117750825$

3. Barth KA, Lawton CD, Touhey DC, et al. The negative impact of anterior cruciate ligament reconstruction in professional male footballers. Knee. 2019;26(1):142-148. doi:10.1016/j.knee.2018.10.004

4. Grassi A, Smiley SP, Roberti Di Sarsina T, et al. Mechanisms and situations of anterior cruciate ligament injuries in professional male soccer players: a YouTube-based video analysis. Eur J Orthop Surg Traumatol. 2017;27(7):967-981. doi:10.1007/s00590-017-1905-0

5. Zaffagnini S, Grassi A, Marcheggiani Muccioli GM, et al. Return to sport after anterior cruciate ligament reconstruction in professional soccer players. Knee. 2014;21(3):731-735. doi:10.1016/j.knee.2014.02.005

6. Weiler R, Monte-Colombo M, Mitchell A, Haddad F. Non-operative management of a complete anterior cruciate ligament injury in an English Premier League football player with return to play in less than 8 weeks: applying common sense in the absence of evidence. BMJ Case Rep. 2015;2015:bcr2014208012-bcr2014208012. doi:10. 1136/bcr-2014-208012

7. Niederer D, Engeroff T, Wilke J, Vogt L, Banzer W. Return to play, performance, and career duration after anterior cruciate ligament rupture: a case-control study in the five biggest football nations in Europe. Scand J Med Sci Sports. 2018;28(10):2226-2233. doi:10.11 11/sms. 13245

8. Waldén M, Hagglund M, Magnusson H, Ekstrand J. Anterior cruciate ligament injury in elite football: a prospective three-cohort study. Knee Surg Sports Traumatol Arthrosc. 2011;19(1):11-19. doi:10. 1007/s00167-010-1170-9

9. Waldén M, Hagglund M, Ekstrand J. UEFA Champions League study: a prospective study of injuries in professional football during the 2001-2002 season. Br J Sports Med. 2005;39(8):542-546. doi:10.1136/bjsm.2004.014571

10. Waldén M, Hägglund M, Ekstrand J. High risk of new knee injury in elite footballers with previous anterior cruciate ligament injury. $\mathrm{Br}$ $J$ Sports Med. 2006;40(2):158-162;. doi:10.1136/bjsm.2005.021055

11. Lundblad M, Waldén M, Hagglund M, Ekstrand J, Thomee C, Karlsson J. No association between return to play after injury and increased rate of anterior cruciate ligament injury in men's professional soccer. Orthop J Sports Med. 2016;4(10):2325967116669708. doi: $10.1177 / 2325967116669708$

12. Waldén M, Krosshaug T, Bjorneboe J, Andersen TE, Faul O, Hagglund M. Three distinct mechanisms predominate in non-contact anterior cruciate ligament injuries in male professional football players: a systematic video analysis of 39 cases. Br J Sports Med. 2015;49(22):1452-1460. doi:10.1136/bjsports-2014-094573

13. Lundblad M, Hagglund M, Thomee C, et al. Medial collateral ligament injuries of the knee in male professional football players: a prospective three-season study of 130 cases from the UEFA Elite Club Injury Study. Knee Surg Sports Traumatol Arthrosc. 2019;27 (11):3692-3698. doi:10.1007/s00167-019-05491-6

14. Lundblad M, Waldén M, Magnusson H, Karlsson J, Ekstrand J. The UEFA injury study: 11-year data concerning $346 \mathrm{MCL}$ injuries and time to return to play. Br J Sports Med. 2013;47(12):759-762. doi:10.1136/bjsports-2013-092305

Open Access Journal of Sports Medicine

\section{Publish your work in this journal}

Open Access Journal of Sports Medicine is an international, peerreviewed, open access journal publishing original research, reports, reviews and commentaries on all areas of sports medicine. The
15. Schulz MS, Russe K, Weiler A, Eichhorn HJ, Strobel MJ. Epidemiology of posterior cruciate ligament injuries. Arch Orthop Trauma Surg. 2003;123(4):186-191. doi:10.1007/s00402-002-0471-y

16. Krutsch W, Zeman F, Zellner J, Pfeifer C, Nerlich M, Angele P. Increase in ACL and PCL injuries after implementation of a new professional football league. Knee Surg Sports Traumatol Arthrosc. 2016;24(7):2271-2279. doi:10.1007/s00167-014-3357-y

17. Lee BK, Nam SW. Rupture of posterior cruciate ligament: diagnosis and treatment principles. Knee Surg Relat Res. 2011;23(3):135-141. doi:10.5792/ksrr.2011.23.3.135

18. Fowler PJ, Messieh SS. Isolated posterior cruciate ligament injuries in athletes. Am J Sports Med. 1987;15(6):553-557. doi:10.1177/ 036354658701500606

19. Becker EH, Watson JD, Dreese JC. Investigation of multiligamentous knee injury patterns with associated injuries presenting at a level I trauma center. J Orthop Trauma. 2013;27(4):226-231. doi:10.10 97/BOT.0b013e318270def4

20. Bushnell BD, Bitting SS, Crain JM, Boublik M, Schlegel TF. Treatment of magnetic resonance imaging-documented isolated grade III lateral collateral ligament injuries in National Football League athletes. Am J Sports Med. 2010;38(1):86-91. doi:10.1177/ 0363546509344075

21. Ekstrand J, Hagglund M, Waldén M. Injury incidence and injury patterns in professional football: the UEFA injury study. $\mathrm{Br}$ J Sports Med. 2011;45(7):553-558. doi:10.1136/bjsm.2009.060582

22. Hagglund M, Waldén M, Bahr R, Ekstrand J. Methods for epidemiological study of injuries to professional football players: developing the UEFA model. Br J Sports Med. 2005;39(6):340-346. doi:10. 1136/bjsm.2005.018267

23. Fuller CW, Ekstrand J, Junge A, et al. Consensus statement on injury definitions and data collection procedures in studies of football (soccer) injuries. Clin J Sport Med. 2006;16(2):97-106. doi:10.1097/ 00042752-200603000-00003

24. Kaeding CC, Leger-St-Jean B, Magnussen RA. Epidemiology and diagnosis of anterior cruciate ligament injuries. Clin Sports Med. 2017;36(1):1-8. doi:10.1016/j.csm.2016.08.001

25. Alentorn-Geli E, Myer GD, Silvers HJ, et al. Prevention of non-contact anterior cruciate ligament injuries in soccer players. Part 1: mechanisms of injury and underlying risk factors. Knee Surg Sports Traumatol Arthrosc. 2009;17(7):705-729. doi:10.1007/ s00167-009-0813-1

26. Thorborg K, Krommes KK, Esteve E, Clausen MB, Bartels EM, Rathleff MS. Effect of specific exercise-based football injury prevention programmes on the overall injury rate in football: a systematic review and meta-analysis of the FIFA 11 and $11+$ programmes. Br J Sports Med. 2017;51(7):562-571. doi:10.1136/bjsports-2016-097066

27. LaPrade RF, Terry GC. Injuries to the posterolateral aspect of the knee. Association of anatomic injury patterns with clinical instability. $\mathrm{Am}$ J Sports Med. 1997;25(4):433-438. doi:10.1177/036354659702500403

manuscript management system is completely online and includes a very quick and fair peer-review system. Visit http://www.dovepress. com/testimonials.php to read real quotes from published authors. 